\title{
Medios de comunicación, violencia y poder $^{1}$
}

\author{
Luis NitRIHUAL VALDEBENITO \\ Universidad de la Frontera (Chile) \\ luis.nitrihual@ufrontera.cl. \\ Javier MAYORGA ROJEL \\ Universidad de la Frontera (Chile) \\ javier.mayorga@ufrontera.cl \\ Juan Manuel FiERro Bustos \\ Universidad de la Frontera (Chile) \\ uanmanuel.fierro@ufrontera.cl
}

Recibido: 31 de agosto de 2014

Aceptado: 10 de marzo de 2015

\section{Resumen}

En este artículo de reflexión nos proponemos como objetivo describir la relación medios de comunicación / poder para lo cual se plantea una revisión de la noción conceptual de dispositivo y las implicaciones que ella tiene para una teoría crítica de los medios de comunicación. Se propone que los medios de comunicación son un dispositivo relevante en la administración de la nuda vida. Para realizar este ejercicio, presentamos ejemplos de la situación de los medios de comunicación chilenos.

Palabras clave: Medios de Comunicación, dispositivo, violencia.

\section{Mass media, violence and power}

\begin{abstract}
In this reflection article we propose aim to describe the media relationship / power to which there is a review of the conceptual notion of device and the implications that it has for critical media theory. It is proposed that media are a relevant device in the administration of nude life. To perform this exercise, we present examples of the situation of the Chilean media.
\end{abstract}

Keywords: Media, device, violence.

\section{Referencia normalizada}

NITRIHUAL VALDEBENITO, Luis; MAYORGA ROJEL, Javier; y FIERRO BUSTOS, Juan Manuel (2015): "Medios de comunicación, violencia y poder". Estudios sobre el Mensaje Periodístico. Vol. 21, Núm. 2 (julio-diciembre), págs.: 1129-1136. Madrid, Servicio de Publicaciones de la Universidad Complutense.

Sumario: 1. Introducción. 2. El papel de los medios. Violencia y crisis políticas. 3. Medios y dispositivo. La administración de la nuda vida. 4. Conclusiones. 5. Referencias bibliográficas.

\section{Introducción}

Hay un análisis interesante respecto al papel desempeñado por los medios de comunicación durante el periodo de la Unidad Popular en Chile en el trabajo de Diego Porta-

1 Artículo producto de los siguientes proyectos de investigación: FONDECYT $\mathrm{n}^{\mathrm{o}}$ 1141289; FONDECYT n ${ }^{\circ}$ 1130542; FONDECYT n ${ }^{\circ} 1120904$, los tres, financiados por el Consejo Nacional de Ciencia y Tecnología. Todos los autores de este artículo son parte del Centro de Investigación Comunicación, Discurso y Poder. Núcleo Científico de Ciencias Sociales. Universidad de La Frontera (Chile). 
les (1983) publicado por el ILET (Instituto Latinoamericano de Estudios Transnacionales) en el marco de un seminario titulado: "Comunicación y Pluralismo: alternativas para la década" y que fue llevado a cabo en México en 1982. Con una distancia de 31 años tal vez no sea una mala idea comenzar por ahí puesto que es necesario recuperar el pensamiento crítico latinoamericano. Este, nos podría suministrar las signaturas para articular una cierta teoría crítica y compleja para pensar la actualidad. Se trata, desde nuestro punto de vista, de un pensamiento crítico pues debe poner entredicho la naturaleza positiva de la sociedad, proponiendo la posibilidad de un mundo mejor y considerando en su análisis al capitalismo como una totalidad superable. Asimismo, se trata, de un pensamiento complejo pues debe permitir articular las distintas variables que articular/desarticulan el capitalismo actual. Como describe Terry Eagleton (2011:21) en relación a la pertinencia y necesidad de una teoría crítica en la actualidad.

Como ya predijera Marx, en nuestra propia época las desigualdades de riqueza se han profundizado hasta niveles extraordinarios. La renta actual de un solo multimillonario mexicano equivale a los ingresos de sus 17 millones de compatriotas más pobres.

Así entonces, nos proponemos como objetivo central en este artículo reflexionar acerca del papel de los medios de comunicación en situaciones de violencia política. Para realizarlo metodológicamente -dada nuestra experiencia y la conmemoración de los 40 años del golpe militar en Chile de 1973- utilizamos "casos afines" que nos ayudan a reelaborar una mirada psicopolítica del lugar de los medios de comunicación en momentos de crisis sociales y de manifestación de violencia o como diría Sloterdijk (2010) de la ira como fenómeno propio de la humanidad.

\section{El papel de los medios. Violencia y crisis políticas}

Pero regresemos al texto de Diego Portales, para él el proceso revolucionario chileno implicó un conjunto de propuestas que de forma sumaria buscaban profundizar la democracia en el marco de la construcción del socialismo; en este mismo contexto se trataba de un programa de redistribución de los beneficios a favor de los sectores asalariados, no obstante ello -señala Portales- las dimensiones comunicacionales de la democratización no fueron abordadas o al menos minusvaloradas. Se aplicó más bien una política de competencia en el mercado ${ }^{2}$ ¿A qué se debe este descuido del proyecto político de la Unidad Popular, según Portales? En lo concreto, a un pacto suscrito por la Unidad Popular y la Democracia Cristiana, pero en un nivel profundo a un problema de interpretación de la naturaleza del Estado chileno y, podríamos agregar nosotros, a la falta de convencimiento por parte de la clase política de izquierda de que los medios de comunicación se desarrollaron desde su origen bajo la marca del oligopolio y que, en este mismo sentido, son un dispositivo clave en los procesos de subjetivación / desubjetivación y de articulación ideológica que fue utilizado, esta historia ya es conocida, por la élites de la oligarquía chilena.

2 Esto coincide con lo que señala un texto clásico de los estudios comunicológicos chilenos; el trabajo de Sunkel y Geoffroy (2001) donde se describe la profusión de prensa política partidaria hasta la fecha del golpe militar de 1973. 
En efecto, lo que se observa en Chile durante el periodo de la Unidad Popular, es un trabajo bastante clásico de construcción de una realidad, sostenida hasta hoy como línea argumental por la derecha política chilena y basada en la idea de una sociedad que se acercaba a la autodestrucción, al flagelo dictatorial del marxismo internacional (ruso en su tiempo, pero actualizado en Bolivia y Venezuela hoy).

Ahora bien, para conseguir este efecto de realidad, al decir barthesiano, deben invocarse formaciones imaginarias que ya desde la fundación del diario chileno El Mercurio se construyeron y que constituyen hoy el núcleo básico de desarticulación del pensamiento de izquierda reducido -claro está- al "comunismo" como máxima negación de la naturaleza humana.

La penetración del emblema antimarxista ha sido tan potente en Chile que hoy se revela en la propia adhesión a los partidos políticos. Lo anterior se demuestra, por ejemplo, en la popularidad que la derecha más dura tiene en los sectores socialmente más pobres del país. Por otro lado, en un nivel teórico más profundo, la consideración de que lo llevado a cabo por el gobierno de Salvador Allende fue antinatural, dictatorial, atentatorio del curso natural de la historia, tiene una relación paralela con la formación de un imaginario que considera que el capitalismo es lo natural, lo único que genera libertad al individuo y que, en consecuencia, es el curso natural de la historia. Con justa razón, Žižek (2012) señala que la tarea central de la ideología dominante es la elaboración e imposición de una narrativa que tiende a historizar y describir las formas sociales en dos tipos: naturales y artificiales. Retomando a Marx en Miseria de la Filosofía, se puede señalar que la característica central de la ideología burguesa es la historización de "toda forma social, religiosa y cultural es histórica, contingente, relativa; toda forma, excepto la suya propia. Una vez hubo una historia, pero ahora ya no hay ninguna historia más" (Žižek, 2012: 27)

Algo similar podemos encontrar en las narrativas de los discursos políticos contingentes en las elecciones presidenciales del año 2013 en Chile. El péndulo se mueve desde miradas de izquierda que piden cambiar la Constitución por considerarla ilegítima, dado que fue impuesta en tiempos de dictadura, a posiciones, más de derecha, que plantean que solo hay que retocar lo que tenemos puesto que es el único camino que da viabilidad al desarrollo del país. Propuestas como la Asamblea Constituyente son, para esta última posición política, una suerte de desviación marxista que podría conducirnos a una nueva debacle política como la sucedida en 1973. La virulencia de este argumento ha sido tal en Chile -lo cual revela la profundidad de conflicto ideológico subyacente- que un reconocido abogado chileno señaló hace poco tiempo en la prensa que en el caso de pensarse en una Asamblea Constituyente el uso de la fuerza para restaurar el orden constitucional: "No se puede descartar nunca; cuando la gente hace trampas en el juego político y sobrepasa la Constitución, la solución puede venir de cualquier lado [...] no puedo predecir, pero sí predigo que si se lleva a cabo el proyecto de sus asesores constitucionales (de Michelle Bachelet) va a haber una crisis institucional en Chile"'3 La propia candidata de la derecha Evelyn Matthei ha señalado

${ }^{3}$ Entrevista a Hermógenes Pérez de Harce aparecida el 3 de junio de 2013 en el diario electrónico El Mostrador. Online: http://www.elmostrador.cl/noticias/pais/2013/06/03/hermogenesperez-de-arce-dice-que-asamblea-constituyente-seria-un-paso-hacia-la-anarquia-en-chile/ 
reiteradamente que la discusión sobre una nueva constitución es ideológica y no afecta realmente la vida cotidiana de las personas. Desde nuestro punto de vista, se trata del momento más elevado de la ideología cuando la política es reducida a la administración gerencial del Estado y, asimismo, cuando se propone que la mirada gerencial no es ideológica. Es decir, allí están los ideológicos y aquí estamos "nosotros" preocupados de la cosas "reales" de la gente concreta. Como señala Žižek en relación a la penetración de la ideología:

Una ideología se "apoderá de nosotros" realmente sólo cuando no sentimos ninguna oposición entre ella y la realidad -a saber, cuando la ideología consigue determinar el modo de nuestra experiencia cotidiana de la realidad [...]. Una ideología realmente triunfa cuando incluso los hechos que a primera vista la contradicen empiezan a funcionar como argumentaciones en su favor (Žižek, 2009: 80).

La tesis de la "doctrina del shock" de Naomi Klein tiene mucho sentido en este y otros casos de la política chilena e incluso, lo cual es aún más duro, en la práctica cotidiana del chileno medio. La violencia y hostilidad que se producen cada vez que hay propuesta de cambio al "curso natural del desarrollo social" son un hecho probado entre la clase política. Hay que seguirle la pista a este permante estado de hostilidad que revive los "oscuros tiempos del marxismo" y las consecuencias que tuvo su implementación. No deja de tener razón Klein (2007) cuando señala que la historia del libre mercado está escrita en base a shocks. También, aunque no hay tiempo para desarrollar esta propuesta en este trabajo, es interesante plantear como la violencia de la dictadura militar cuyo punto culmine fue la existencia de lugares de tortura y exterminio, produjo una marca de inseguridad y miedo que tiene un correlación en la psicopolítica del capitalismo salvaje instalado en Chile. Sin ir más lejos, tal vez cabe aventurar la hipótesis ya propuesta por Agamben (2007) del Estado de Excepción permanente de la sociedad actual.

En esta medida, no hay que ir muy lejos en el tiempo para darnos cuenta que esta línea argumental está presente con total vigencia en el discurso político de los candidatos de la derecha política chilena. Esta se reduciría, en una línea, al retroceso que implicaría que los comunistas participarán en el gobierno. Es interesante repensar como las articulaciones, vistos como sistemas discursivos, funcionan en torno a esquemas bastante rígidos que son tomados de, por llamarlo de algún modo, "bancos simbólicos" administrados por quienes detentan el poder en su minuto.

Tal vez agregar una consideración más a este estado de emergencia permanente. No hay que ir muy lejos, sino sólo sentarse frente a un noticiario, para ver el relato de una crisis manifestada en forma de violencia por parte de cada vez más amplios sectores de la población mundial. Las revueltas en Brasil están allí para mostrarnos que la población ya no se traga la idea de un desarrollo sustentado sólo en el crecimiento económico. Hay un desprestigio generalizado de la clase política. Allí donde había un Berlusconi en Italia o un Zapatero en España, Chile presentaba a una empresario como presidente. Este ha caído a niveles insospechados de rechazo. Así en Chile-evidentemente queda para la memoria del lector todas las otras innumerables crisis en distintas zonas del planeta- se vive una grave situación de pérdida de credibilidad en la clase política. Nos parece que esta situación no terminará por más retoques que se 
hagan al modelo y más bien veremos brotes de violencia callejera cada vez con más frecuencia. ¿Qué hacer con esta violencia? Claramente los discursos de derecha en el mundo llaman a esto delincuencia, terrorismo, etc. Lo articulan como discurso de campaña prometiendo mayor seguridad en las calles, fin de la delincuencia, una policía fuerte en el control de la delincuencia. No obstante ello, lo que se juega es algo más profundo y tiene que ver con el descontento y la desconfianza más o menos generalizado en la clase política. Sin dudas, esta situación es grave como señala Žižek:

"Lo que llamamos "crisis de la democracia no ocurre cuando la gente deja de creer en su propio poder, sino, al contrario, cuando deja de confiar en las élites, en aquellos que supuestamente saben por ella y proporcionan las pautas a seguir, cuando sienten la ansiedad de sospechar que el (verdadero) trono está vacío" (Žižek, 2012: 58).

\section{Medios y dispositivo. La administración de la nuda vida}

Ahora bien, como primera consideración teórica general podemos señalar que la administración de los imaginarios, lo cual es materia de nuestro interés actual, es llevada a cabo hoy de manera privilegiada por los medios de comunicación. Regresando a la idea planteada por Diego Portales (1983) la no consideración de este poder de los medios de comunicación constituyó una de las debilidades de la propuesta de la Unidad Popular. Los medios, como lo señaló Lippmann y más tarde, Chomsky, construyen el consenso. Estos son parte de un gran dispositivo que administra la subjetivización / desubjetivación de los sujetos. La pregunta que cabe hacerse, en este marco, es qué clase de sujetos son los construidos por los medios de comunicación. Evidentemente, el capitalismo, con su profusión de dispositivos, está generando procesos de desubjetivación. En un excelente ejemplo que propone Agamben (2011: 262) para explicar este proceso: "Quien se deje asir en el dispositivo del "teléfono móvil", sea cual sea la intensidad del deseo que lo empuje, no adquiere una nueva subjetividad, sino únicamente un número por medio del cual podrá, eventualmente ser controlado". Ahora bien, al igual que este ejemplo, quien se deje asir por los medios se convertirá en un indicador de audiencia. De igual modo, la profusión de medios electrónicos no genera, como piensan las miradas ingenuas, sujetos más informados sino sólo un sujeto paradójico totalmente atravesado por gigantescos procesos de desubjetivación (Agamben, 2011: 262) y profunda y paradójicamente desinformado.

Parece interesante, desde un nivel teórico que nos permite la articulación entre la acción de los medios y la sujeción de los sujetos, la noción de dispositivo planteada por Foucault y retomada por Agamben (2011) en un breve y brillante trabajo titulado "¿Qué es un dispositivo? Antes que entrar en esto, no podemos dejar de señalar, coincidiendo con el mismo Agamben, la consideración general de que la lectura de este texto, como cualquier proceso de interpretación, deja de ajustarse en algún punto a la lectura original para seguir su propio curso y, porqué no, traicionar al propio autor. Comencemos considerando la noción de dispositivo foucaultiana, pues puede ayudarnos en determinar el papel de los medios de comunicación en la articulación del modo de producción ideológica. Hay que tener en cuenta una primera afirmación que destaca que los medios de comunicación son articulaciones históricas y socialmente determinadas (Sierra, 2011). Los medios existen en una cierta estructura, en un determinado 
marco de acción donde desempeñan algunas funciones específicas y otras más bien generales. Para Williams (2003: 173), por ejemplo, los medios de prensa surgen asociados a la clase media.

El diario fue la creación de la clase media comercial, principalmente en el siglo XVIII. Sirvió a esta clase con noticias importantes para la conducción de los negocios, y en ese carácter se estableció como una institución financieramente independiente.

Williams agrega, además, algunas funciones específicas que desempeñaron los medios de prensa y que tienen relación con la instalación de determinadas normas y valores que la burguesía buscaba cristalizar. En este mismo sentido, Eagleton (1999) ha descrito con toda precisión las funciones ideológicas que desempeñaron los medios de prensa desde el siglo XVII en adelante. Estos instalaron valores estéticos y éticos capitales en la formación de una esfera pública fracturada por las luchas sociales.

Ahora bien, si nos atenemos a lo que señala Agamben (2011) con respecto a las características que tiene un dispositivo encontramos que este:

1. Es algo heterogéneo que incluye todo, desde algo lingüístico a algo no lingüístico: discursos, instituciones, edificios.

2. Un dispositivo tiene una función estratégica inscrita en una relación de poder.

3. Es una red pues incluye una episteme, que es aquello que una sociedad determinada entiende por científico/no científico.

De este modo, podemos coincidir en señalar que el término Dispositivo parece referir a la disposición de una "serie de prácticas y de mecanismos (conjuntamente lingüísticos y no lingüísticos, jurídicos, técnicos y militares) con el objetivo de hacer frente a una urgencia y de conseguir un efecto" (Agamben, 2011, p. 3). En este sentido, Agamben señala que la noción de dispositivo de Foucault, que se puede pesquisar a partir del vocablo latino Dispositio tiene toda una tradición teológica ${ }^{4}$, viene a implicar una serie de saberes, medidas e instituciones cuyo objetivo es administrar y controlar el comportamiento de los hombres. De este modo:

Las sociedades contemporáneas se presentan como cuerpos inertes atravesados por gigantescos procesos de desubjetivación, los cuales no responden a ninguna subjetivación real. Como consecuencia de ello, surge el eclipse de la política que suponen los sujetos y las identidades reales (el movimiento obrero, la burguesía, etcétera) y el triunfo de la economía, es decir, de una pura actividad de gobierno que no persigue otra cosa que su propia reproducción (Agamben, 2011: 262).

Es en este panorama que tenemos que insertar el papel de los medios como dispositivos que tiene una función importante en la economía, en la actividad de gobierno que busca su propia reproducción. El miedo y la administración de la violencia parecieran capitales como parte de este trabajo. Como ya señalaba Portales (1983), la no

\footnotetext{
4 Para un mayor desarrollo de esta temática Cfr. el texto de Giorgio Agamben (2009). El Reino y la Gloria. Barcelona: Pre-Textos. En el se muestra el vínculo entre Oikonomía, Economía y teología. Esta se desarrollaría en el cristianismo mediante la entrega de la Oikonomía, es decir, la administración y gobierno de los hombres, a Cristo.
} 
advertencia, por parte de la intelectualidad de izquierda, del lugar que tienen los medios de comunicación en la generación y regeneración del capitalismo decadente que vivimos en la actualidad, puede ser un grave error cuando nos enfrentemos a la posibilidad de construir otra sociedad mejor.

\section{Conclusiones}

En términos generales, podemos concluir que los medios de comunicación son un dispositivo clave en los procesos de subjetivización / desubjetivación de las sociedades contemporáneas. En este marco, los medios constituyen una suerte de bancos simbólicos que administran los imaginarios que articulan la realidad. Resulta interesante entender los discursos como "sistemas discursivos" que funcionan de manera articulada y que se construyen durante largos trayectos históricos donde los medios comunicación desempeñan un papel vital.

En el caso chileno es posible observar la construcción de estos imaginarios en la oposición radical entre comunismo/democracia como dos opuestos que constituyen parte del proyecto inicial de un sistema mediático de marcado carácter oligárquico. En este sentido, los discursos políticos contingentes (al 2013) se mueven entre un conformismo moderado como el del actual conglomerado político de la Nueva Mayoría (antigua Concertación) que apela a su electorado prometiendo cambiar lo posible dentro de los marcos normativos vigentes y, por otro lado, la derecha política que apela a los viejos miedos del comunismo que representa el regreso de Michelle Bachelet y la posibilidad de instalación de un socialismo como imagen invertida de los valores democráticos liberales.

Con todo, parece que la situación de violencia callejera no cambiará por más retoques que se hagan a un modelo que en el mundo se encuentra en crisis y que amenaza con hacer estallar a las multitudes, conectadas por el descontento generalizado y movilizadas por la certeza de que el trono de la política se está cayendo a pedazos.

\section{Referencias bibliográficas}

AGAMBEN, Giorgio (2011): “¿Qué es un dispositivo?”. Sociológica, año 26, núm. 73, pp. 249-264.

AGAMBEN, Giorgio (2007): Estado de Excepción. Buenos Aires, Adriana Hidalgo Editora.

EAGLETON, Terry (2011): Por qué Marx tenía razón. Barcelona, Península.

EAGLETON, Terry (2009): La función de la crítica literaria. Barcelona, Siglo XXI.

KLEIN, Naomi (2007): La doctrina del shock: el auge del capitalismo del desastre. Barcelona, Paidós.

PORTALES, Diego (1983): "El movimiento popular y las comunicaciones: reflexiones a partir de la experiencia chilena", en REYES, Fernando: Comunicación alternativa y búsquedas democráticas. México, ILET y Friedrich Ebert Stiftung.

SLOTERDIJK, Peter (2010): Ira y Tiempo. Madrid, Siruela. 
SIERRA, Francisco (2011): "Consumo cultural y poder mediático", en ALBORNOZ, Luis: Poder, medios, cultura. Una mirada crítica desde la economía política de la comunicación, pp. 189-218. Buenos Aires, Paidós.

SUNKEL, Guillermo y GEOFFROY, Esteban. (2001): Concentración Ecónomica de los medios de comunicación. Santiago de Chile, LOM.

WILLIAMS, Raymond (2003): La larga revolución. Buenos Aires, Nueva visión.

ŽIŽEK, Slavoj (2012): Bienvenidos a tiempos interesantes. La Paz, Bolivia: Editorial Txalaparta.

ŽIŽEK, Slavoj (2011): Primero como tragedia, después como farsa. Madrid, Akal.

ŽIŽEK, Slavoj (2009): El sublime objeto de la ideología. Buenos Aires, Siglo XXI. 